\title{
A New Technique to Select Mild Strains of Cucumber mosaic virus
}

Takashi Kobori, Kyoto Prefectural Institute of Agricultural Biotechnology, Kyoto 619-0244, Japan; Bo-Song Ryang, Kyoto BIKEN Laboratories, Inc., Kyoto 611-0041, Japan; Tomohide Natsuaki, Genomics Research Institute, Utsunomiya University, Utsunomiya 321-8505, and Laboratory of Plant Pathology, Faculty of Agriculture, Utsunomiya University, Utsunomiya 321-8505, Japan; and Yoshitaka Kosaka, Kyoto Prefectural Institute of Agricultural Biotechnology

\section{ABSTRACT}

Kobori, T., Ryang, B.-S., Natsuaki, T., and Kosaka, Y. 2005. A new technique to select mild strains of Cucumber mosaic virus. Plant Dis. 89:879-882.

An efficient technique to select a good attenuated virus to control Cucumber mosaic virus (CMV) disease was developed. Preliminary screenings were conducted to assess the virulence of virus recovered from dark-green islands and yellow tissues of mosaic leaves of Nicotiana rustica after co-inoculation with an attenuated mutant P2bR46C of CMV and its original severe isolate Pepo. All single-lesion isolates (SLIs) obtained from dark-green islands had the attenuated P2bR46C phenotype, but the SLIs from yellow tissue had either the virulent Pepo or the P2bR46C phenotype. When Pepo-infected N. rustica and tomato plants were grown at 15 or $36^{\circ} \mathrm{C}$ for 30 days, 17 of 288 SLIs obtained from the treated leaves elicited mosaic and dark-green spots without malformation. Dark-green tissue from each plant infected with 1 of these 17 SLIs then was used to inoculate one plant of $N$. rustica. All 17 plants had either very mild mosaic or no visible symptoms. One of these potential mild strains, 36R37, had an amino acid substitution on the $2 b$ gene encoding the $2 \mathrm{~b}$ protein. Isolate $36 \mathrm{R} 37$ also was highly cross-protective, and its symptom attenuation was stable for three serial host passages. After cold or heat treatment, the dark-green tissue proved to be a good source for isolating mild strains of the virus.

Additional keywords: cross-protection, temperature treatment

Pre-infection with one virus can prevent symptom expression on plants after subsequent infection with closely related strains of the same virus. Known as crossprotection (22), this ability has been harnessed to control virus diseases in several crops. However, the selection and production of mild strains for this control strategy has been dependent upon various empirical methods (15). Thus, this time-consuming process for obtaining stable mild strains has been a major factor prohibiting our progress in using mild strains to control viral diseases. Development of an effective selection method should further our progress in finding mild strain candidates.

Cucumber mosaic virus (CMV) is the type member of the Cucumovirus group, which contains a tripartite single-stranded and plus-sense RNA genome and infects

Corresponding author: T. Kobori

E-mail: covo@kab.seika.kyoto.jp

This study was performed through Special Coordination Funds for Promoting Science and Technology (Leading Research Utilizing Potential of Regional Science and Technology) of the Ministry of Education, Culture Sports, Science and Technology of the Japanese Government.

Accepted for publication 7 April 2005.

DOI: 10.1094/PD-89-0879

(C) 2005 The American Phytopathological Society more than 1,000 plant species (21). CMV encodes at least five proteins. The $2 \mathrm{~b}$ protein encoded on the RNA 4A, subgenomic RNA from the RNA 2 (3), is a determinant of virulence and a suppressor of RNA silencing $(2,4,8,27)$.

CMV causes severe diseases and economic losses in cereal, fruit, vegetable, and ornamental plants worldwide $(10,21)$. Therefore, it is important to obtain useful mild strains of CMV for cross-protecting these crops. In this study, we describe an efficient method to select mild strains of CMV.

\section{MATERIALS AND METHODS}

Viruses. Two isolates of CMV, an attenuated point mutant P2bR46C (T. Kobori, Y. Kosaka, and T. Natsuaki, unpublished data) and its original severe isolate Pepo (23), were used for tests to select mild strains. These isolates were propagated in Nicotiana rustica, and infected leaves were stored at $-80^{\circ} \mathrm{C}$ before being used as standard inoculum. The virus also was purified from the infected leaves for use as inoculum. The inoculum was extracted or diluted in $0.1 \mathrm{M}$ phosphate buffer (PB; pH 7.0).

Temperature treatment and singlelesion isolations. $N$. rustica and tomato (Lycopersicon esculentum cv. MomotaroT93) were inoculated with the Pepo isolate at the third- to fifth-leaf stage and at the cotyledon stage, respectively. Immediately, the plants were grown in a growth chamber at 15,24 , or $36^{\circ} \mathrm{C}$ for 30 days. All the uninoculated upper leaves were harvested, and these leaf extracts in $0.1 \mathrm{M}$ PB were used to mechanically inoculate Chenopodium quinoa leaves. Single local lesions (SLLs) that developed on C. quinoa at 2 or 3 days after inoculation were ground individually in $0.1 \mathrm{M} \mathrm{PB}$ and transferred to $N$. rustica seedlings at the third- or fourth-leaf stage. The plants then were grown in a temperature-controlled $\left(25^{\circ} \mathrm{C}\right)$ greenhouse.

Cross-protection assay. Cotyledons of 10-day-old tomato seedlings were mechanically inoculated with mild isolates 36R37 and SRO (28). Control seedlings were inoculated with $0.1 \mathrm{M}$ PB only. At 15 days post inoculation (dpi), the third true leaves were mechanically inoculated with the challenge isolate Pepo at a concentration of purified virus of $25 \mu \mathrm{g} / \mathrm{ml}$. Symptom development was observed for 25 days after the challenge inoculation. The plants were scored for disease severity according to the following scale: $0=$ no visible symptoms; 1 = mosaic or mild filiform leaf; 2 = mosaic and mild filiform leaf; and 3 = mosaic, mild filiform leaf, and stunting. Disease severity or percentage of diseased plants was statistically analyzed with the Kruskal-Wallis analysis of variance test or the Fisher's exact test or $\chi^{2}$ test of independence at $P=0.01$ (Bonferroni adjusted probabilities).

Viral cDNA synthesis. Simple direct tube-reverse transcription (SDT-RT) was used for cDNA synthesis from infected leaves (24). Ground leaf sap with $10 \mathrm{mM}$ phosphate-buffered saline (PBS) was added to a microcentrifuge tube. After removing the sap, the tube was washed twice with PBS containing 0.5\% Tween 20. RNase-free water added to the tube was used as the template for the RT reaction. First-strand cDNA was synthesized using primer $\mathrm{CMV}^{\prime} \mathrm{NSR}$ (5'-CCCCCGCATGCGGCCGCTGGTCTCCTTTTAGAGG-3'), complementary to the $3^{\prime}$ terminal common sequence of CMV RNAs, and the First-Strand cDNA synthesis kit (Amersham Biosciences, Piscataway, $\mathrm{NJ}$ ) at $37^{\circ} \mathrm{C}$ for $60 \mathrm{~min}$.

RT-polymerase chain reaction-based single-strand conformation polymorphism analysis. RT-polymerase chain reaction-based single-strand conformation polymorphism (RT-PCR-SSCP) analysis 
(20) was used to detect any nucleotide mutations on the $2 b$ gene of 17 attenuated candidates obtained after temperature treatments. The $2 b$ gene was amplified from viral cDNA by PCR using primers SSCP-2bF (5'-CCAATAAACAGCGAAAGAAATATG- $\left.3^{\prime}\right)$ and SSCP-2bR (5'CGGAAGGGGAGGTTTCA-3') that were designed from Pepo RNA 2 (accession no. AB124835). The PCR products $(2 \mu \mathrm{l})$ mixed in $18 \mu \mathrm{l}$ of loading buffer $(10 \mathrm{ml}$ of formamide, $0.4 \mathrm{ml}$ of $0.5 \mathrm{M}$ EDTA [pH 8.0], $0.01 \%$ [wt/vol] xylene cyanol, $0.01 \%$ [wt/vol] bromphenol blue) were treated for $5 \mathrm{~min}$ at $85^{\circ} \mathrm{C}$ and then were transferred immediately to ice. The samples were separated by electrophoresis for $60 \mathrm{~min}$ at $200 \mathrm{~V}$ on $6 \%$ Tris-borate-EDTA (TBE)polyacrylamide gel at $10^{\circ} \mathrm{C}$. The band pattern on the gel was visualized by silver staining (Silver Stain KANTO III; KANTO KAGAKU, Toyko, Japan). The PCR product having nucleotide mutations indicates a different band pattern from that of Pepo.

RT-PCR restriction fragment length polymorphism analysis. RT-PCR-based restriction fragment length polymorphism (RT-PCR-RFLP) analysis was used to identify Pepo and P2bR46C (18). A PCR of 30 cycles was performed using KOD Dash (TOYOBO, Osaka, Japan) with primers R2-F (5'-ACTCCAACTGGCTCGTATGG- $3^{\prime}$ ) and CMV3'NSR and the following parameters: denaturation at $95^{\circ} \mathrm{C}$ for $30 \mathrm{~s}$, annealing at $58^{\circ} \mathrm{C}$ for $1 \mathrm{~min}$, and extension at $68^{\circ} \mathrm{C}$ for $1 \mathrm{~min}$. The PCR products were treated using restriction enzyme $H h a \mathrm{I}$ and then electrophoresed with 3\% TBE-agarose gel; two fragments of about 500 and $100 \mathrm{bp}$ were produced for P2bR46C, but none for Pepo.

Determination of nucleotide sequence on $2 \boldsymbol{b}$ gene. The $2 b$ gene was amplified by PCR using primers SSCP-2bF and SSCP$2 \mathrm{bR}$ as described. The PCR product then was separated using 3\% TBE agarose gel. The product at the expected size was sliced from the gel and eluted by GFX PCR DNA and Gel Band Purification kit (Amersham Biosciences). The sequence reaction was performed using CEQ DTCS Quick Start kit (Beckman Coulter, Fullerton, CA), and the resultant samples were analyzed with a CEQ-8000 (Beckman Coulter). Nucleotide sequence analysis was carried out by GENETIX-MAC (Software Development, Tokyo, Japan).

\section{RESULTS}

Selection of mild isolates from darkgreen islands. We first inoculated N. rustica plants with a mixed inoculum of an attenuated point mutant $\mathrm{P} 2 \mathrm{bR} 46 \mathrm{C}$ and its original severe Pepo isolate. Dark-green islands (DGIs) and yellow tissues on mosaic leaves were carefully detached with razor blades at $13 \mathrm{dpi}$, and leaf extracts from each region then were used to inoculate C. quinoa. Extracts from DGI tissue produced far fewer SLLs than did yellowtissue extracts (data not shown). When $N$.

Table 1. Symptom expression on leaves of Nicotiana rustica after inoculation with single-lesion isolates (SLIs) from dark-green islands or yellow tissues from mosaic symptoms on N. rustica after coinfection with severe and mild isolates

\begin{tabular}{|c|c|c|c|c|c|}
\hline \multirow[b]{2}{*}{ Inoculum } & \multirow[b]{2}{*}{$\operatorname{Region}^{\mathrm{x}}$} & \multirow[b]{2}{*}{ No. tested ${ }^{y}$} & \multirow[b]{2}{*}{ No. of SLIs ${ }^{z}$} & \multicolumn{2}{|c|}{$\begin{array}{l}\text { No. of SLIs with } \\
\text { phenotype of isolatew }\end{array}$} \\
\hline & & & & P2bR46C & Pepo \\
\hline \multirow[t]{2}{*}{ Pepo + P2bR46C } & Y & 20 & 20 & $6(6)$ & $14(0)$ \\
\hline & DGI & 20 & 7 & $7(7)$ & $0(\mathrm{NT})$ \\
\hline \multirow[t]{2}{*}{ Pepo } & Y & 20 & 20 & 0 (NT) & $20(\mathrm{NT})$ \\
\hline & DGI & 50 & 50 & $0(\mathrm{NT})$ & $50(\mathrm{NT})$ \\
\hline
\end{tabular}

${ }^{w}$ Number of SLIs with P2bR46C pattern in reverse-transcription polymerase chain reaction restriction fragment length polymorphism (RT-PCR-RFLP). Symptoms were observed nearly every day for 3 weeks. Viral RNA extracts from third and fourth upper leaves were used for RT-PCR-RFLP; NT = not tested.

${ }^{\mathrm{x}}$ Region on mosaic leaves; $\mathrm{Y}=$ yellow tissue and $\mathrm{DGI}=$ dark-green-island tissue.

${ }^{\mathrm{y}}$ Number of single lesions tested; single lesion was used to inoculate Nicotiana rustica.

${ }^{\mathrm{z}}$ Viral infection was checked by enzyme-linked immunosorbent assay.

Table 2. Selection efficiency of mild variants of Cucumber mosaic virus from the plants of Nicotiana rustica infected with a virulent Pepo isolate after cold or heat treatment

\begin{tabular}{llccc}
\hline & & & \multicolumn{2}{c}{ Symptoms on . rustica $^{\mathbf{x}}$} \\
\cline { 3 - 5 } Temperature $\left({ }^{\mathbf{o}} \mathbf{C}\right)^{\mathbf{y}}$ & Plant & No. of SLIs tested & SM/Mal & MM/GS \\
\hline 36 & Tomato & 52 & 50 & 2 \\
& N. rustica & 48 & 47 & 1 \\
15 & Tomato & 88 & 81 & 7 \\
& N. rustica & 100 & 93 & 7 \\
24 & N. rustica & 30 & 30 & 0 \\
\hline
\end{tabular}

${ }^{x}$ Symptoms were observed nearly every day for 3 weeks. $\mathrm{SM}=$ severe mosaic, Mal = leaf malformation, $\mathrm{MM}=$ mild mosaic, $\mathrm{GS}=$ dark-green spot.

y Plants were held at each temperature for 30 days after inoculation with the Pepo isolate.

${ }^{\mathrm{z}}$ SLIs $=$ single-lesion isolations. rustica then was inoculated with 1 of 20 SLLs, all SLIs originating from the DGIs developed a phenotype identical to that of $\mathrm{P} 2 \mathrm{bR} 46 \mathrm{C}$ at $14 \mathrm{dpi}$ (Table 1). In addition, these phenotypes corresponded with results from the concomitant RT-PCR-RFLP analysis. On the other hand, all SLIs obtained from DGIs on leaves infected with Pepo alone caused severe mosaic and malformations (Table 1). These results indicated that attenuated variants within diseased plants could be efficiently isolated from DGIs on the mosaic leaves, but the virus concentration was low.

Selection of mild variants from darkgreen tissue after cold or heat treatment. We obtained 17 out of the total of 288 SLIs by treatments at 15 and $36^{\circ} \mathrm{C}$. These 17 SLIs caused milder symptoms, such as mosaic and dark-green spots without malformation (Table 2; Fig. 1), than did Pepo. On the other hand, all SLIs from a control treatment at $24^{\circ} \mathrm{C}$ expressed severe mosaic and symptoms similar to Pepo. More mild isolates tended to be produced by the cold treatment $(7.4 \%)$ than by the heat treatment $(3.0 \%)$.

When the leaf extract from each darkgreen spot produced by these mild SLIs was used to inoculate $N$. rustica, the inoculated plants either did not develop any visible symptoms or the symptoms were a very mild mosaic (Fig. 2). To determine the stability of such symptom attenuation, 2 of 17 mild isolate candidates, 15T3 and 36R37, selected by screening from coldand heat-treated plants, respectively, underwent three serial passages through $N$. rustica and single-lesion isolations using C. quinoa. Both isolates were stable and maintained their mild symptom phenotype during the host passages. In addition, all plants inoculated with each of 15 SLLs from $15 \mathrm{~T} 3$ or $36 \mathrm{R} 37$ induced mild symptoms similar to the intact isolate. These results suggest that mild variants are effec-

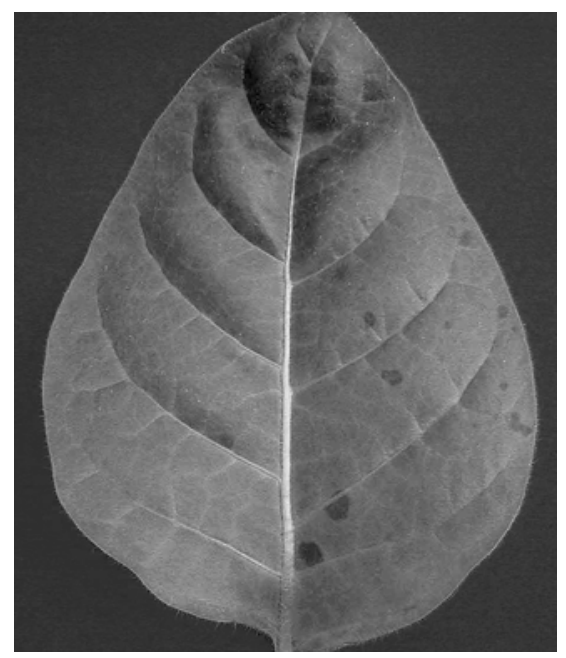

Fig. 1. Typical dark-green spots on second upper leaf of Nicotiana rustica 15 days after inoculation with a single local lesion isolate obtained after heat treatment. 
tively obtained by dark-green tissue isolation after cold or heat treatment.

The $2 b$ gene sequence and crossprotective ability of a promising mild variant. The $2 b$ gene encoding the $2 b$ protein of $\mathrm{CMV}$ has numerous functions associated with the virulence $(2,4,8)$. In RT-PCR-SSCP analysis of the $2 b$ gene of 17 mild candidates obtained in our selection trials, only isolate $36 \mathrm{R} 37$ yielded a band pattern different from that of Pepo (Fig. 3A). This result indicated that 36R37 had a nucleotide mutation or mutations on the $2 b$ gene. We then determined the nucleotide sequence of $2 b$ gene of this mild variant 36R37. Although the $2 b$ gene nucleotide lengths of 36R37 and Pepo were the same (333 nucleotides), 36R37 had a nucleotide mutation at position 122 on the $2 \mathrm{~b}$ open reading frame, which involved an amino acid substitution at position 41 (Fig. $3 \mathrm{~B}$; Pro to Leu) in a putative phosphorylation domain (16).

We also examined the cross-protective ability of 36R37 in tomato. An attenuated SRO isolate with a useful protective ability (28) was used as a positive control. At 25 days after the challenge inoculation, none of the isolates caused any visible symp- toms on tomato plants, and isolate $36 \mathrm{R} 37$ had a high degree of cross-protection that was similar to that of SRO (Table 3).

\section{DISCUSSION}

In this study, we isolated mild variants from dark-green leaf tissue after cold or heat treatments. Other researchers also have obtained mild isolates for practical use after both cold and heat treatments, which can induce mutations on viral genomic RNAs $(7,11-13,17,19)$. In our experiments, mild isolates appeared to be more efficiently selected by cold treatment than by heat treatment (Table 2). Szittya et al. (25) have reported that low temperature inhibits RNA silencingmediated resistance against virus. Moreover, several groups have reported that the loss of silencing suppression is associated with viral symptom attenuation $(5,14)$. For mild variants in diseased plants that were maintained at low temperature, low temperature may provide better conditions for survival than for those at high temperature.

Several studies have been reported in which the DGIs on leaves of diseased plants, protected from infection by closely
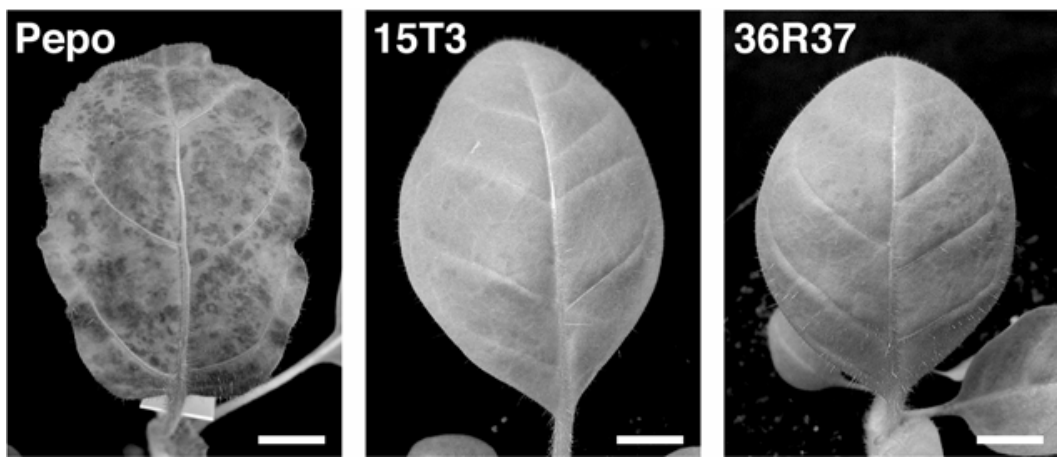

Fig. 2. Symptoms on upper leaves on Nicotiana rustica 15 days after inoculation with various isolates of Cucumber mosaic virus $(\mathrm{CMV})$. Pepo $=$ Pepo isolate, $15 \mathrm{~T} 3=$ mild strain isolated after cold treatment, and 36R37 = mild strain isolated after heat treatment. Mild isolates were isolated from darkgreen spots. Bars $=2 \mathrm{~cm}$.

related viruses, contained little or no virus $(1,6)$. However, no evidence of the presence of mild strains in DGIs has been reported (9).

In our screening test of the mild mutant P2bR46C from DGIs on mosaic leaves that had been co-infected with the original severe isolate Pepo, only P2bR46C was isolated from the DGIs. On the other hand, mild variants were not isolated from DGIs on leaves with severe mosaic of plants inoculated with Pepo alone, but mild variants were isolated from these tissues after cold or heat treatment. These results suggest that using inoculum containing mild variants such as the cold- or heat-treated sample is necessary to select mild strains from DGIs.

The 36R37 isolate had an amino acid substitution in the $2 \mathrm{~b}$ protein. A mutation that reduced RNA-silencing suppression also attenuated symptoms, as described earlier $(5,14)$. In addition, the 2bdefective CMV caused mild symptoms (4). Therefore, the amino acid substitution on $36 \mathrm{R} 37 \mathrm{2b}$ protein may reduce the suppression of silencing, resulting in symptom attenuation. However, other mild isolates obtained in this study did not have the mutation on the $2 b$ gene, suggesting that a viral factor or factors other than the $2 \mathrm{~b}$ protein also is associated with symptom attenuation. In our study, two mechanisms are possible: symptom attenuation may be due to a mechanism other than RNA silencing, and a viral factor other than the $2 \mathrm{~b}$ protein also may suppress RNA silencing because the 2b-defective CMV variant has suppressed amplicon-mediated RNA silencing (26).

This is the first report of the isolation of a mild strain from dark-green islands. Although we used CMV as a model in this study, most plant viruses cause mosaic symptoms on more than one host. Therefore, dark-green tissue isolation after mutagenesis is a technique that may be

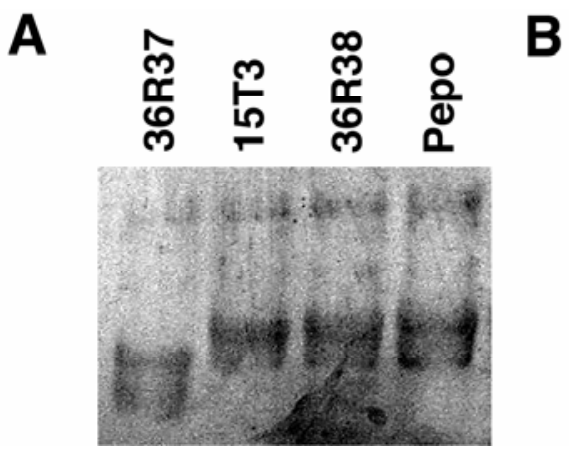

\section{$\begin{array}{llllllllllll}\mathrm{R} & \mathrm{G} & \mathrm{H} & \mathrm{K} & \boldsymbol{S} & \boldsymbol{L} & S & E & \mathrm{R} & \mathrm{A} & \mathrm{R}\end{array}$ 36R37 106 CGAGGTCACAAAAGTCTCAGCGAGAGAGCGCGT 138

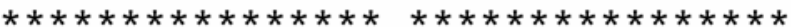 \\ Pepo 106 CGAGGTCACAAAAGTCCCAGCGAGAGAGCGCGT 138

$\begin{array}{lllllllllll}\mathrm{R} & \mathrm{G} & \mathrm{H} & \mathrm{K} & \boldsymbol{S} & \boldsymbol{P} & S & E & \mathrm{R} & \mathrm{A} & \mathrm{R}\end{array}$

41

Fig. 3. Nucleotide sequence analysis of the $2 b$ gene of $36 \mathrm{R} 37$ isolate. A, Reverse-transcription polymerase chain reaction-based single-strand conformation polymorphism (RT-PCR-SSCP) analysis of the $2 b$ gene of mild strain candidates. The $2 b$ gene of each isolate was amplified by RT-PCR. The PCR products were separated by electrophoresis $(200 \mathrm{~V}$ for about $60 \mathrm{~min})$ on $6 \%$ Tris-borate-EDTA-polyacrylamide gel at $10^{\circ} \mathrm{C}$. The band pattern was visualized by silver staining. 36R37 = Mild strain isolated after heat treatment, 15T3 = mild strain isolated after cold treatment, $36 \mathrm{R} 38=$ virulent strain obtained after heat treatment, and Pepo = Pepo isolate. B, Partial nucleotide sequence (from nucleotide position 106 to 138) of the $2 b$ open reading frame on $36 \mathrm{R} 37$ (DDBJ/EMBL/GenBank accession no. AB182559) and Pepo (accession no. AB124835), and the translational amino acid residues (amino acid position from 35 to 46) is shown. Asterisk (*) indicates matching nucleotide position. Bold lettering indicates a different amino acid residue. Residues in italics indicate a putative phosphorylation domain (16). 
Table 3. Cross-protection ability of mild Cucumber mosaic virus (CMV) 36R37 isolate against Pepo isolate of CMV in tomato

\begin{tabular}{lccc}
\hline Pre-inoculated isolate $^{\mathbf{x}}$ & No. of plants tested & ${\text { Diseased plants }(\boldsymbol{\%})^{\mathbf{y}}}$ & Disease severity $^{\mathbf{z}}$ \\
\hline 36R37 & 41 & $0.0 \mathrm{a}$ & $0 \mathrm{a}$ \\
SRO & 44 & $4.5 \mathrm{a}$ & $0.1 \mathrm{a}$ \\
Noninoculated & 30 & $76.7 \mathrm{~b}$ & $1.8 \mathrm{~b}$ \\
\hline
\end{tabular}

${ }^{x}$ Purified virus was used as inoculum at a concentration of $50 \mu \mathrm{g} / \mathrm{ml}$. The plants infected with $36 \mathrm{R} 37$ or SRO expressed no visible symptoms during testing.

y Symptoms were observed 25 days after the challenge inoculation with Pepo at a concentration of 25 $\mu \mathrm{g} / \mathrm{ml}$. The different letter indicates a significant difference, based on the Fisher's exact test or $\chi^{2}$ test of independence at $P=0.01$ (Bonferroni adjusted probabilities).

${ }^{\mathrm{z}}$ Plants were scored for disease severity on a scale of 0 to 3 , where $0=$ no visible symptoms; $1=$ mosaic or mild filiform leaf; $2=$ mosaic and mild filiform leaf; and $3=$ mosaic, mild filiform leaf, and stunting. Means within the column followed by different letters were significantly different at $P=$ 0.01 in Kruskal-Wallis analysis of variance test.

applicable for several plant viruses. This alternative technique has promise in furthering our progress in controlling viral diseases through cross protection with attenuated viruses.

\section{ACKNOWLEDGMENTS}

We thank K. Hanada (National Institute of Agrobiological Sciences) for the gift of the CMV SRO isolate.

\section{LITERATURE CITED}

1. Atkinson, P. H., and Matthews, R. E. F. 1970. On the origin of dark green tissue in tobacco leaves infected with tobacco mosaic virus. Virology 40:344-356.

2. Brigneti, G., Voinnet, O., Li, W. X., Ji, L. H., Ding, S. W., and Baulcombe, D. C. 1998. Viral pathogenicity determinants are suppressors of transgene silencing in Nicotiana benthamiana. EMBO J. 17:6739-6746.

3. Ding, S. W., Anderson, B. J., Haase, H. R., and Symons, R. H. 1994. New overlapping gene encoded by the cucumber mosaic virus genome. Virology 198:593-601.

4. Ding, S. W., Li, W. X., and Symons, R. H. 1995. A novel naturally occurring hybrid gene encoded by a plant RNA virus facilitates long distance virus movement. EMBO J. 14:5762-5772.

5. Ding, X. S., Liu, J., Cheng, N. H., Folimonov, A., Hou, Y. M., Bao, Y., Katagi, C., Carter, S. A., and Nelson, R. S. 2004. The Tobacco mosaic virus $126-\mathrm{kDa}$ protein associated with virus replication and movement suppresses RNA silencing. Mol. Plant-Microbe Interact. 17:583-592.

6. Fulton, R. W. 1951. Superinfection by strains of tobacco mosaic virus. Phytopa- thology 41:579-592.

7. Goto, T., Iizuka, N., and Komochi, S. 1984. Selection and utilization of an attenuated isolate of pepper strain of tobacco mosaic virus. Ann. Phytopathol. Soc. Jpn. 50:221-228. (In Japanese)

8. Guo H. S., and Ding S. W. 2002. A viral protein inhibits the long range signaling activity of the gene silencing signal. EMBO J. 21:398407.

9. Hull, R. 2002. Matthews' Plant Virology, 4th ed. Academic Press, San Diego, CA.

10. Kaper, J. M., and Waterworth, H. E. 1981. Cucumoviruses. Pages 257-332 in: Handbook of Plant Virus Infections. E. Kurstak, ed. North Holland Biomedical Press, Amsterdam.

11. Kosaka, Y., and Fukunishi, T. 1993. Attenuated isolates of soybean mosaic virus derived at a low temperature. Plant Dis. 77:882-886.

12. Kosaka, Y., and Fukunishi, T. 1997. Multiple inoculation with three attenuated viruses for the control of cucumber virus disease. Plant Dis. 81:733-738.

13. Kosaka, Y., Nakazono, E., and Natsuaki, T. 2001. Attenuated isolates of Bean yellow mosaic virus obtained by cold treatment. (Abstr.) Jpn. J. Phytopathol. 67:142. (In Japanese)

14. Kubota, K., Tsuda, S., Tamai, A., and Meshi, T. 2003. Tomato mosaic virus replication protein suppresses virus-targeted posttranscriptional gene silencing. J. Virol. 77:11016-11026.

15. Lecoq, H., and Raccah, B. 2001. Crossprotection: Interactions between strains exploited to control plant virus disease. Pages 177-192 in: Biotic Interactions in PlantPathogens Associations. M. J. Jeger and N. J. Spence, eds. CABI Publishing, Nosworthy Way, UK.

16. Lucy, A. P., Guo, H. S., Li, W. X., and Ding, S.
W. 2000. Suppression of post-transcriptional gene silencing by a plant viral protein localized in the nucleus. EMBO J. 19:1672-1680.

17. Nagai, Y. 1987. Production of C-1421, an attenuated mutant of pepper strain of tobacco mosaic virus. Ann. Phytopathol. Soc. Jpn. 53:168-174. (In Japanese)

18. Nakazono, E., Suzuki, M., Kosaka, Y., Natsuaki, T., Okuda, S., and Mizu, O. 1998. Discrimination between an attenuated CM95 isolate and severe strains of cucumber mosaic virus (CMV) by RT-PCR-based RFLPs. (Abstr.) Ann. Phytopathol. Soc. Jpn. 64:427. (In Japanese)

19. Ohshima, N. 1975. The control of tomato mosaic virus disease with attenuated virus of tomato strain of TMV. Rev. Plant Prot. Res. 8:126-135.

20. Orita, M., Iwahana, H., Kanazawa, H., Hayashi, K., and Sekiya, T. 1989. Detection of polymorphisms of human DNA by gel electrophoresis as single-strand conformation polymorphisms. Proc. Natl. Acad. Sci. USA 86:2766-2770.

21. Palukaitis, P., Roosinck, M. J., Dietzgen, R. G., and Franki, R. I. B. 1992. Cucumber mosaic virus. Adv. Virus Res. 41:281-348.

22. Pennazio, S., Roggero, P., and Conti, M. 2001. A history of plant virology. Cross protection. Microbiologica 24:99-114.

23. Saiga, T., Fujiwara, M., Saitoh, H., Ohki, S. T. and Osaki, T. 1998. Comparative analysis for replication and movement of cucumber mosaic virus in Cucumis figarei and C. melo. Ann. Phytopathol. Soc. Jpn. 64:255-263.

24. Suehiro, N., Matsuda, K., Okuda, S., and Natsuaki, T. 2005. A simplified method for obtaining plant viral RNA for RT-PCR. J. Virol. Methods 125:67-73.

25. Szittya, G., Silhavy, D., Molnár, A., Havelda Z., Lovas, A., Lakatos, L., Bánfalvi, Z., and Burgyán, J. 2003. Low temperature inhibits RNA silencing-mediated defence by the control of siRNA generation. EMBO J. 22:633640.

26. Taliansky, M., Kim, S. H., Mayo, M. A., Kalinina, N. O., Fraser, G., McGeachy, K. D., and Barker, H. 2004. Escape of a plant virus from amplicon-mediated RNA silencing is associated with biotic or abiotic stress. Plant J. 39:194-205.

27. Voinnet, O. 2001. RNA silencing as a plant immune system against viruses. Trends Genet. 17:449-459.

28. Zenbayashi, R., Hanada, K., and Tochihara, H. 1987. Control of tomato mosaic disease by spray inoculation of attenuated strains of cucumber mosaic virus. Proc. Kanto-Tosan Plant Prot. Soc. 34:50-51. (In Japanese) 